\title{
Design and control of grid-connected solar-wind integrated conversion system with DFIG supplying three-phase four-wire loads
}

\author{
Arjun Kumar GB, Shivashankar, Keshavamurthy
}

Department of Electronics \& Communication Engineering, Sri Venkateshwara College of Engineering, Bengaluru, India

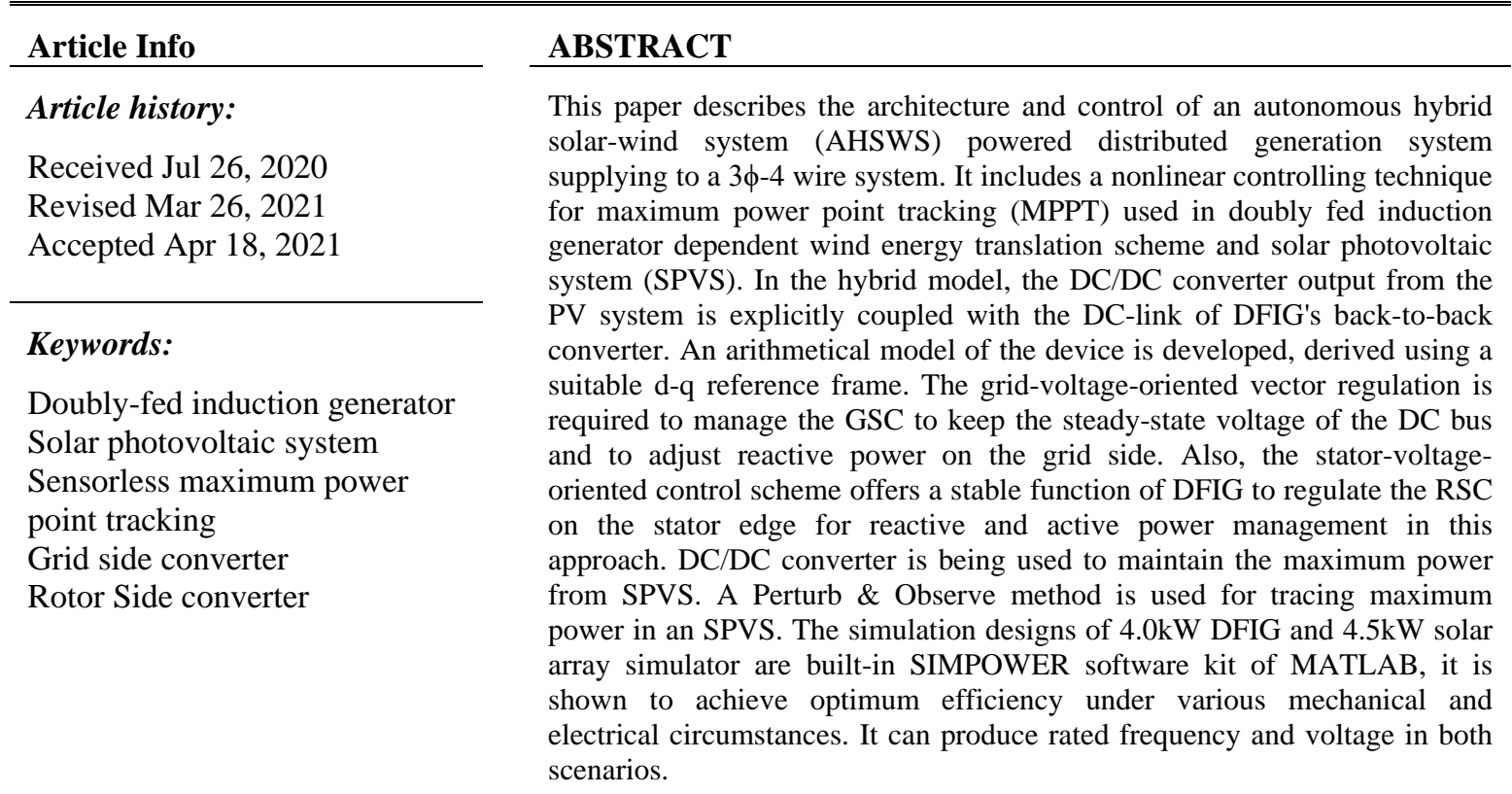

This is an open access article under the CC BY-SA license.

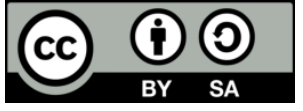

\section{Corresponding Author:}

Arjun Kumar GB

Department of Electronics \& Communication Engineering

Sri Venkateshwara College of Engineering

Bengaluru, Karnataka, India

Email: arjungb@gmail.com

\section{INTRODUCTION}

The global problems of the $21^{\text {st }}$ century include climate change, energy costs, and growing energy demand. This can be addressed in part by adding efficient, distributed, and renewable energy resources. But strengthening performance in all aspects of renewable energy generation is often a major issue. This has a direct or indirect impact on the sustainable development of the energy providers in contexts of energy costs and generator durability. The greater the performance, the reduced the losses, and thus the lifetime of a generator is significantly higher compared to traditional systems. In the current global context nearly total installed capacity reaching 597 GW in 2019 [1], and the DFIG derived wind energy generation device is a prevalent choice based on technical availability and control feasibility. Although, the DFIG's efficiency is still a concern. Similar wind energy systems based on DFIG have developed over the past couple of decades. 
At first, DFIG-centered wind energy conversion schemes with sensor-less, grid connections were suggested [2]-[6]. In [7] suggested various scheme will consider the effective optimization approach to solve micro-grid optimization issues with limitations. In [8], power quality in the electric grid and to integrate wind electricity production utilizing Stockwell's transform (ST) throughout different operating cases. Likewise, in the earlier phase, standalone DFIG off-grid systems have been suggested as outlined [9]-[12] for isolated area electrification. It was found that generator performance and power supply intermission are the main challenges in these suggested methods. These concerns also need to be properly discussed for sustainable wind power technology development given efficiency and energy costs [13]. Concerning DFIG efficiency, initiatives have been created to regulate the device through weakening the DFIG's flux level, as presented [14], [15]. But the low torque and magnetic saturation of both the high velocity and the low-velocity operational areas restrict their use for a large range of speeds. [16] A double VSI-DFIG with DC output utilizing a rotor current-oriented stator frequency control scheme was suggested to avoid the abovementioned speed limitations. Throughout this method of control, the frequency of stator is not variable as regards efficiency. Effective control models have been developed to increase the performance of DFIG dependent WEGS in [17]-[19]. Such arrangements do not take into account the copper losses of the machine, although it is a significant loss factor. The next problem concerning the WEGS is the existence of intermittent wind power systems. The previous concerns can be addressed appropriately by wind and photovoltaic hybrid systems with battery backup, as naturally wind and solar PV generations complement each other [20].On this basis, a hybrid wind and solar-PV generation model has been proposed in [21].The DC-link voltage controller and performance of DFIG were the biggest challenges in this control configuration, restricting its implementations for microgrids dominated by renewable energies and large speed service respectively.

The fundamental benefit of the DFIG-SPVS hybrid model is to minimize the price of conventional structures. The low-cost model in renewable energy markets, particularly in rural areas, is quite competitive. To further minimize costs, a sensor-less maximum point tracking technique (MPPT) for both the PV source and hybrid device is proposed. The key idea of this technique is to utilizing output power to calculate input power. The grid side converter (GSC) and rotor side converter (RSC) power can be used in operation to calculate the SPVS power according to the DC-link balance of the hybrid model.

The following sections describe a detailed estimate algorithm. Such a sensor-less MPPT technique has been implemented and effectively implemented to an autonomous PV device in our previous work [22]. This strategy will reduce the costs in comparison with the hybrid model using a conventional MPPT model. The price of the hybrid model is substantially cheaper with the use of less power electronic converters and less appropriate sensors. In the low voltage ride-through sources must be enhanced to compensate for the changing voltage within the grid during a fault [23]. MATLAB/Simulink is used to develop and evaluate the complete system. This article introduces an autonomous hybrid solar-wind system (AHSWS) system utilizing a WES-DFIG and SPVS with $3 \phi$, 4-line battery energy storage supply grid. The sensor-less MPPT hybrid model can execute well with changes in atmospheric circumstances and control conditions, as can be seen with simulation results. Three converters can work smoothly and in collaboration, while the DFIG mode of operation differs both in above and below rated synchronous speed. Also, the back-to-back converter manages the SPVS DC power and maintains the DC-link balanced even without an inverter. Finally, it is concluded that in all sorts of operating circumstances the complete module can provide rated voltage and frequency, maintaining DFIG current stable and the integrated sensor-less device can be an effective and reliable solution for different SPVS and DFIG setups.

The key objective of this article is demonstrating

- To design an autonomous hybrid solar-wind system (AHSWS) system utilizing a WES-DFIG and SPVS with $3 \phi$, 4-line battery energy storage supply grid

- To implementation of a sensor-less wind Speed control scheme dependent on Adaptive Backstepping.

- To achieve optimum efficiency under various mechanical, electrical circumstances

\section{STUDIED MODEL AND DESIGN COMPONENTS}

The autonomous hybrid solar-wind system (AHSWS) model utilizing a WES-DFIG and SPVS with $3 \phi$, 4-line battery energy storage supply grid is investigated in this study and is represented in Figure 1. In this configuration, the DC-DC converter output is connected to the back-to-back DC-link converter. An inverter of the SPVS is then removed. This will minimize the costs of the overall device. In this study, the chopper converter is Buck-Boost (в-в), it has a very steady functioning and quick reaction and it maintains the maximal generation of power from SPVS. The maximal power is provided to the DC-link voltage. The DC power can then be converted into AC power by RSC and GSC, which is supplied to the rotor or grid. The 
synchronization of these converters to manage power flow is examined and detailed in the simulation analysis. A sensor-less control scheme for the hybrid model is developed. This approach will decrease the number of SPVS sensors, thereby minimizing the cost of the hybrid model

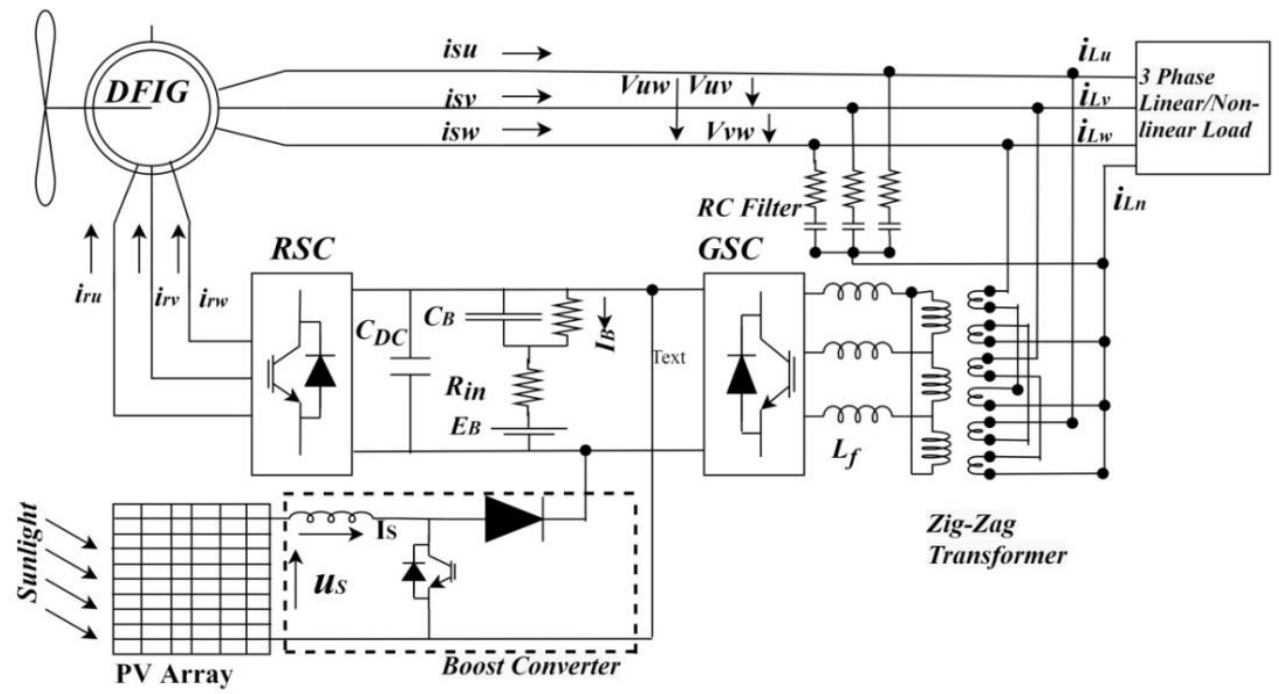

Figure 1. Representation of the autonomous hybrid solar-wind system (AHSWS) with a battery energy system.

The AHSWS is developed for a distributed generation scheme with a maximal load requirement of $4 \mathrm{KW}$ and a mean load of $2 \mathrm{KW}$ for a few households. The $19 \%$ capacity utilization factor is deemed for the solar and wind system blocks. The maximum rated capacity of solar panels $\left(P_{M_{\text {s srated }}}\right)$ and wind turbines $\left(P_{M_{-} \text {Wrated }}\right)$ is considered as $4 \mathrm{KW}$. The entire system contains two voltage converters: the RSC and the GSC, which are attached back-to-back at the DC end as shown in Figure 1. The RSC and GSC AC ends are attached to the rotor windings and the load ports, correspondingly. RSC regulates the wind turbine speed to obtain the wind MPPT. The solar power supplied to the DC bus via the DC-DC boost converter is also configured with the solar MPPT. GSC supplies rated frequency and voltages at the point of the common link.

\section{DFIG AND SPVS MODELING}

DFIG and SPVS arithmetic equations are addressed in this part. Such models are extremely important to evaluate DFIG and SPVS functions and controlling strategies.

\subsection{SPVS Model}

An identical SPV module circuit is presented in Figure 2. This module is involved in the diode and current source connected to parallel. The output resistor and the diode primarily evaluate the SPV module characteristics. The arithmetic equation association among SPVS and voltage-current could be described as (1)

$$
I_{P V}=I_{L}-I_{D}\left[\exp \left(\frac{q * V_{P V}+q * I * R_{S}}{A * K * T}\right)-1\right]
$$

where, $V_{P V}$ and $I_{P V}$ are SPVS voltage and current correspondingly, $I_{D}$-saturation current of diode, $q$-charge of an electron, $A$-diode material factor, $K$-Boltzmann constant, $T$-absolute temperature, and $R_{S}$-series resistor. The characteristic of the SPV system is highly affected by environmental factors such as radiation and temperature. An MPPT technique is thus essential to maintain the maximal power output of the SPV unit. Representative $I V$-curves of SPVS is shown in Figure 3. 


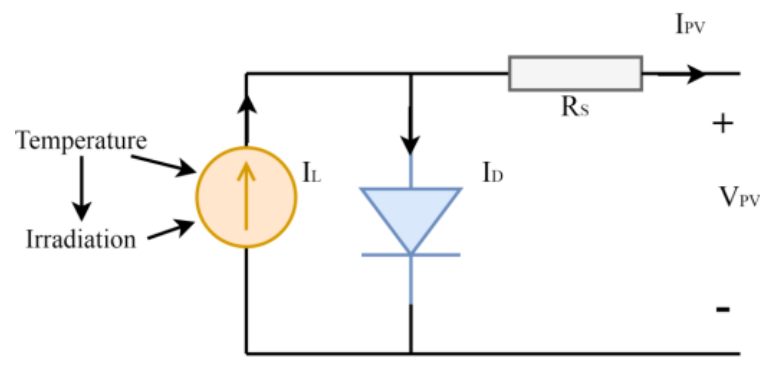

Figure 2. PV Equivalent circuit
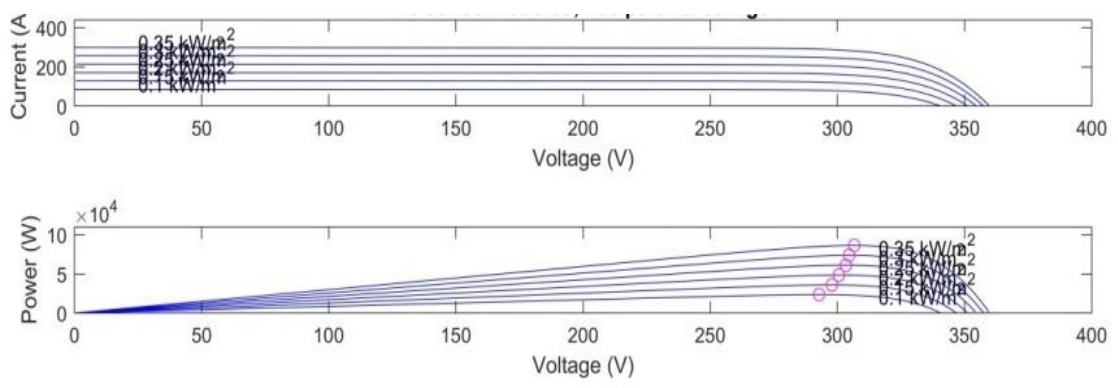

Figure 3. IV-curves of PV

\subsection{DFIG model}

In several research studies, DFIG-WTs are suggested and established. The DFIG model and implementation are described in detail. This research article discusses only basic work-related equations. The relation between the stator flux and current the occurs in the stator-flux comparison framework is,

$$
\begin{aligned}
& i_{d s} * L_{s}+i_{d r} * L_{m}=\psi_{s} \\
& i_{q s} * L_{s}+i_{q r} * L_{m}=0
\end{aligned}
$$

where, $i_{q r}, i_{d r}, i_{q s}$, and $i_{d s}$ are q-axis rotor, $d$-axis rotor, q-axis stator, and $d$-axis stator current correspondingly, $\psi_{s^{-}}$stator flux, $L_{s}$ and $L_{m}$ are stator and magnetic inductance correspondingly. Since the DFIG stator is directly linked with the grid, the stator voltage formulas are indicated as (4). The stator power (6) can be determined based on (3) and (5)

$$
\begin{aligned}
& v_{d s}=0 \\
& v_{q s}=V_{G} \simeq \omega_{s} * \psi_{s} \\
& P_{S}=\frac{3}{2}\left(v_{q s} * i_{q s}\right)=-\frac{3}{2} * V_{G} * \frac{L_{m}}{L_{s}} * i_{q r} \\
& Q_{S}=\frac{3}{2}\left(v_{q s} * i_{d s}\right)=\frac{3}{2} * \frac{V_{G}^{2}}{\omega_{s} * L_{s}} * \frac{L_{m}}{L_{s}} * i_{q r}-\frac{3}{2} * V_{G} \frac{L_{m}}{L_{s}} * i_{d r}
\end{aligned}
$$

where, $Q_{S}, P_{S}, v_{q S}$, and $v_{d s}$ are reactive, active, $q$-axis and $d$-axis of stator voltage correspondingly, $V_{G}$-grid voltage, $\omega_{s^{-}}$angular speed correspondingly. Equation (6-7) specifically notes that stator powers in terms of $q$ axis and d-axis rotor currents can be autonomously regulated. Firstly, reference rotor currents were determined for the corresponding stator powers. The RSC is then regulated to maintain the current of the rotor equal to the reference levels.

The standard cube law formula gives the mechanical power $P_{M}$ from the wind turbine.

$$
P_{M}=0.5 * \rho * A * V_{W}^{3} * C_{P}
$$


where, $A$-blades swept area, $V_{W}$-wind velocity, $\rho$-air density, and $C_{P}$-power coefficient. $C_{P}$ is dependent on the blade $Y$, when the pitch angle of the blade is continual. Some of the various equations for estimating the $C_{P}$. In this study $C_{P}$ is obtained as followed,

$$
C_{P}=0.5(\Upsilon-5.60) \exp (-0.170 * \Upsilon)
$$

where the $V_{W}$ and the speed of generator ratio are specified for the tip speed ratio $(Y)$. If the power coefficient is maximized, wind energy will provide the maximum mechanical power.

$$
\begin{aligned}
& r=\left(\frac{\omega_{R} * r}{\eta_{g} * V_{W}}\right) \\
& \eta_{g}=\left(\frac{\omega_{M R^{*}} r}{\gamma * V_{R W}}\right)
\end{aligned}
$$

The integrated model includes a 4.0KW wind turbine with a radius of $3.0 \mathrm{~m}$ and a maximum TSR of 5.660. $V_{R W}$ and $\omega_{M R}$ is the optimum acceptable rated speed of wind and generator speed correspondingly. $\omega_{M R}$ is selected as $198 \mathrm{rad} / \mathrm{s}$, which correlates to the generator rotational speed per $W_{m p p t} V_{R W}$ of $9.0 \mathrm{~m} / \mathrm{sec}$. Consequently, the gear ratio $\eta_{g}$ as estimated from (11) is given as $\eta_{g}=11.66$ DFIG is implemented to produce $4.0 \mathrm{~kW}$ at the rated wind velocity. Ignoring losses, rated input $\left(P_{I N_{-} R A T E D}\right)$, stator $\left(P_{S_{-} R A T E D}\right)$ and rotor $\left(P_{R_{-} R A T E D}\right)$ power are correlated as,

$$
P_{I N \_R A T E D}=P_{R_{-} R A T E D}+P_{S_{-} R A T E D}
$$

and,

$$
P_{S_{-} R A T E D}=\frac{P_{I N \_R A T E D}}{\left(1+\left|S_{P_{-} R A T E D}\right|\right)}
$$

$S_{P_{-} R A T E D}$ is the slip-on DFIG rated power, turbine speed is $110.0 \mathrm{rad} / \mathrm{sec}$ to $198.0 \mathrm{rad} / \mathrm{sec}$. The associated slip range for the generator is -0.267 to 0.30 . Therefore, the maximal $P_{S_{-} R A T E D}$ stator power equivalent to $P_{M W \text { rated }}$ at slip $S_{P R A T E D}=-0.2670$ is $3.15 \mathrm{~kW}$. A wound rotor motor with a capacity $3.0 \mathrm{~kW}$ is enough for a wind turbine of $4.0 \mathrm{~kW}$; The RSC satisfies the reactive power demand.

\subsection{DC-bus voltage}

Optimum slip is 0.30 which is equal to $110.0 \mathrm{rad} / \mathrm{sec}$ speed of rotor the maximal voltage of rotor $V_{R_{-} M A X M}=0.3 * 415-124.50 \mathrm{~V}$. The DC-voltage of battery $V_{B}$ is,

$$
V_{B}>\left\{\frac{\left[1.64 * V_{L V}\right]}{\varkappa_{i}}\right\}
$$

RSC \& GSC line voltage $V_{L V}$ is chosen $0.125 \mathrm{kV}$, modulation index $\varkappa_{i}$ is chosen unity, and then $V_{B}$ should also be more than $0.204 \mathrm{kV} . V_{B}$ is selected for $0.240 \mathrm{kV}$ in the developed scheme.

\section{CONTROL ALGORITHM}

Oriented vector control approach for the control of the autonomous hybrid solar-wind system as displayed in Figure 1. This control approach is committed to the power converter consisting of the back-toback converter, categorized into an RSC and GSC. The grid-voltage-oriented vector regulation is required to manage the GSC to keep the steady-state voltage of the DC bus and to adjust reactive power on the grid side. Also, the stator-voltage-oriented control scheme offers a stable function of DFIG to regulate the RSC on the stator edge for reactive and active power management [24], [25].

\subsection{Grid side converter control}

The vector control approach employed satisfies the two key aims in the GSC. Firstly, manage the voltage of the DC bus, secondly manage the reactive power interchanged two-ways between the rotor and grid side. Therefore, its indirect axis element becomes zero by associating the grid Voltage Vector with the synchronous direct axis frame. The GSC control formulas and grid power representations are shown in the below equation (15-20). 


$$
\begin{aligned}
& V_{f d}=-\left(R_{f} i_{d g}+L_{f} * \frac{d i_{d g}}{d t}\right)+V_{s d}+\omega_{s} L_{f} i_{q g} \\
& V_{f q}=-\left(R_{f} i_{q g}+L_{f} * \frac{d i_{q g}}{d t}\right)-\omega_{s} L_{f} i_{d g} \\
& P_{g}=1.5 *\left(V_{s d} i_{d g}+V_{s q} i_{q g}\right) \\
& Q_{g}=1.5 *\left(V_{s q} i_{d g}-V_{s d} i_{q g}\right) \\
& V_{s q}=0 \\
& P_{g}=1.5 * V_{s d} i_{d g} \\
& Q_{g}=-\left(1.5 * V_{s d} i_{q g}\right)
\end{aligned}
$$

Where, $V_{f q}$ and $V_{f d}$ are vector elements of the GSC output voltage, $V_{s d}, i_{q g}$, and $i_{d g}$ are grid voltage and current correspondingly. Depending on the indication of a non-zero slip $(S)$ ratio, a portion of the real power produced by DFIG is exchanged with the grid via the rotor that may provide/consume grid power in above and below rated synchronous modes, accordingly. The (19)-(20) indicates that real power and accordingly DC bus voltage could be regulated via $i_{d g}$, while $i_{q g}$ can regulate the grid's reactive power flow. Figure 4 illustrates this technique. Thus, the current controller development comes from (21), (22).

$$
\begin{aligned}
& V_{f d}=-K_{P I} \Delta i_{d g}-K_{I I} * \int \Delta i_{d g} d t-\left(V_{s d}+\omega_{s} L_{f} i_{q g}\right) \\
& V_{f q}=-K_{P I} \Delta i_{q g}-K_{I I} * \int \Delta i_{q g} d t-\left(\omega_{s} L_{f} i_{d g}\right)
\end{aligned}
$$

Here, $\Delta i_{d g}=i_{d g}^{*}-i_{d g}$

$$
\Delta i_{q g}=i_{q g}^{*}-i_{q g} \text {. }
$$

The integral and proportional component of the internal current loop is $K_{I I}$ and $K_{P I}$ respectively. The angular orientation voltage of the grid can be identified through a PLL, with a better standard in expressions of steadiness and transient reaction. Such a locked angle is utilized to convert device parameters into the $d$ - $q$ reference point. The output voltage of the PI regulator keeps the steady voltage of the DC bus, which measures the error among the reference, and determined DC bus voltage and produces $i_{d g}^{*}$. Although $i_{q g}^{*}$ is fixed to null to mitigate the reactive power on the grid edge, the GSC supplies the required magnetizing energy via the DFIG rotor. Ultimately the calculated reference $\left(i_{q g}^{*}, i_{d g}^{*}\right)$ and grid current $\left(i_{q g}, i_{d g}\right)$ are contrasted and handled by internal current PI regulators to produce sufficient GSC signals.

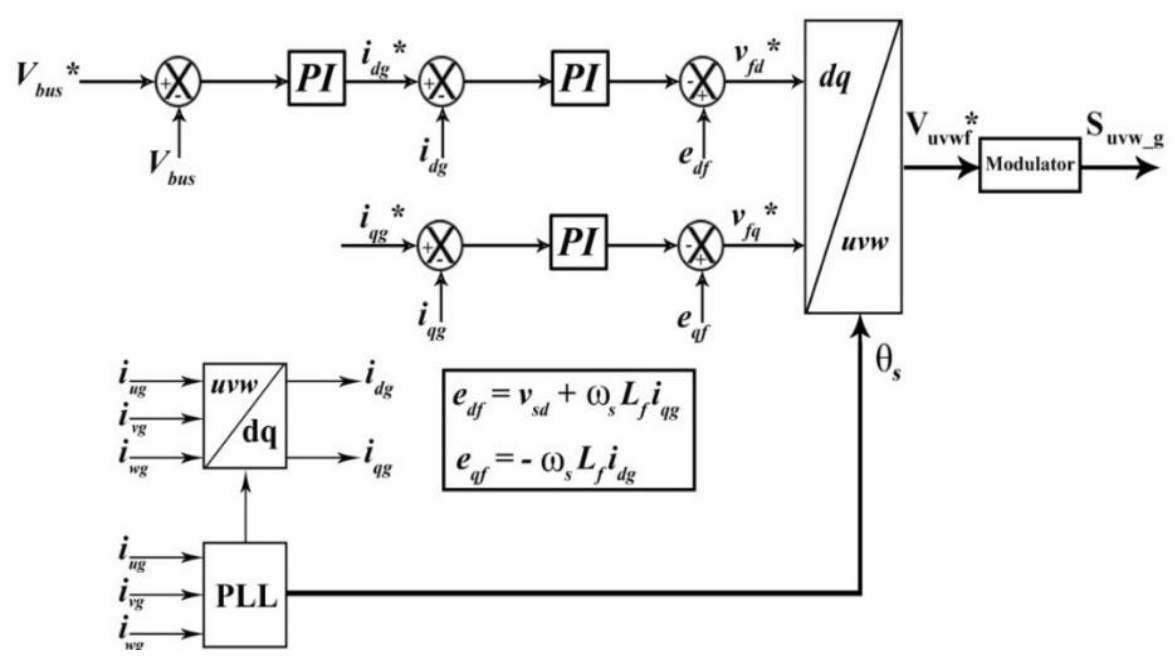




\subsection{Rotor side converter control}

Figure 4. Grid side converter control

The RSC is essential for regulating the DFIG in grid interconnected DFIG-centered WECS to collect the optimal accessible and nominal mechanical power in the wind turbine and to keep the unit power factor in the stator. By ignoring the stator's resistance, and considering a balanced grid voltage, the stator's magnetic flux is assumed to be constant which is enforced by the grid. With vector of stator voltage is oriented through the direct axis, then the stator flux voltage described as.

$$
\begin{aligned}
& V_{s q}=\omega_{s} * \psi_{s d} \\
& V_{s d}=-\omega_{s} * \psi_{s q}
\end{aligned}
$$

Since the stator's active and reactive power is provided in:

$$
\begin{aligned}
& P_{s}=-1.5 * \frac{L_{m}}{L_{s s}} * V_{s q} i_{r q} \\
& Q_{s}=\frac{3}{2} \frac{V_{s q}^{2}}{\omega_{s} L_{s s}}+\frac{3}{2} V_{s q} \frac{L_{m}}{L_{s s}} i_{r d}
\end{aligned}
$$

The steady state equation for rotor voltage is,

$$
\begin{aligned}
& V_{s d}=R_{r} i_{r d}+\sigma L_{r r} * \frac{d i_{r d}}{d t}-\left(\sigma \omega_{\mathrm{r}} L_{r r} i_{r q}\right) \\
& V_{r d}=R_{r} i_{r q}+\sigma L_{r r} * \frac{d i_{r q}}{d t}+\left(\sigma \omega_{r} L_{r r} i_{r d}+\omega_{r} * \frac{L_{m}}{L_{s s}} \Psi_{s d}\right)
\end{aligned}
$$

Where, $=L_{r r}-\left(\frac{L_{m}^{2}}{L_{s s}}\right)$, is leakage coefficient of machine. $i_{r q}$ regulates stator reactive power, whereas the stator active power is regulated by $i_{r d}$ from the stator power equation (25) and (26). Similarly, by incorporating MPPT, the required optimum electro-magnetic torque can compel the DFIG to produce the maximum accessible power onto the grid. The equation of torque is represented as (29),

$$
T_{E M}=1.5 * P * \frac{L_{m}}{L_{s s}} * \Psi_{s d} i_{r q}
$$

The control technique of RSC is outlined in Figure 5. If the stators function at unity power factor, the supply of reactive power from the stator edge to the grid is adjusted to zero. Thus $i_{r q}$ can be derived from equation (26). To determine the maximal power operating points for the turbine, it is achieved from the turbine power curve characteristics.

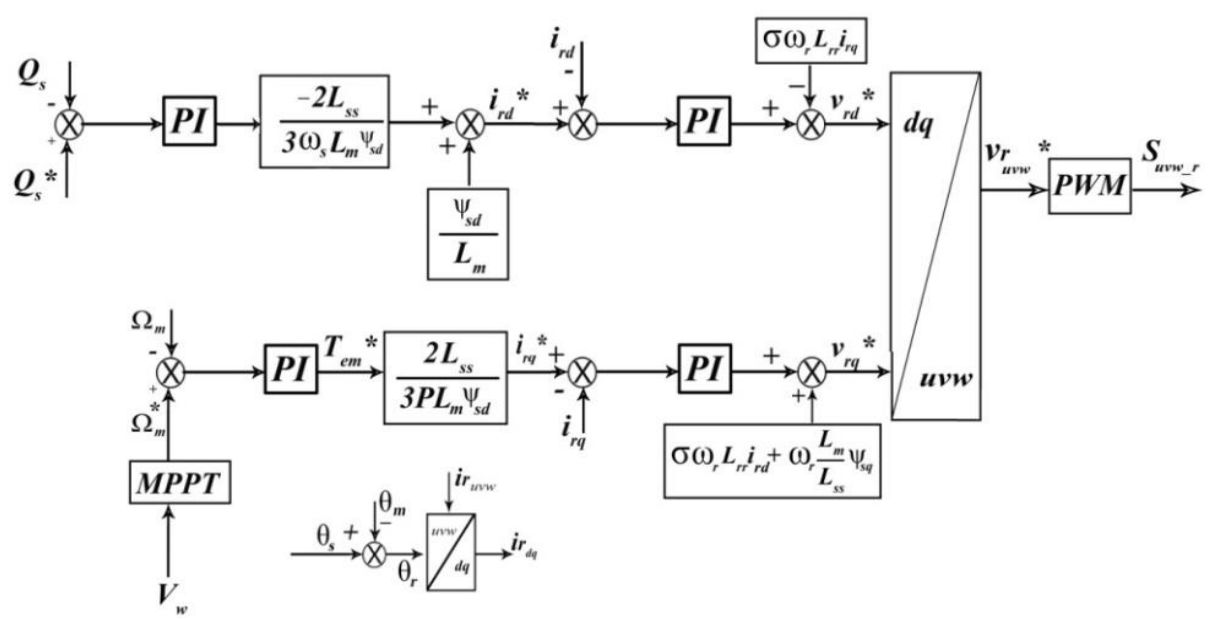

Figure 5. Rotor side converter control. 


\subsection{Wind MPPT}

In this scheme, MPPT is attained by maintaining the maximum tip speed ratio; it is the ratio of the turbine velocity at the tip of a blade to wind speed, towards its maximum value, i.e. by adjusting the maximal rotor speed reference $\Omega_{M}{ }^{*}$ towards its correspondent evaluated wind velocity $V_{W}$, it can be computed from lookup tables. The controller law, when $\Omega_{M}{ }^{*}$ is obtained and then contrasted with real rotor mechanical velocity, $T_{E M}^{*}$ is analyzed utilizing a proportional-integral controller, consequently, $i_{r d}^{*}$ can be determined from (29). Then, the real rotor currents $i_{r q}$ and $i_{r d}$ are contrasted to the reference rotor currentsi $i_{r q}^{*}$ and $i_{r d}^{*}$ until being managed to utilize the internal current controller of PI. Under similar procedures to those utilized for GSC, and then introduced two cross-terms, to eventually produce the control signals in the RSC.

\subsection{SPVS-MPPT control technique}

The greatest problem with SPVS is that the output power is highly depended on the load power and climate circumstances. Thus, a DC/DC converter is being used to maintain the maximum power from PV irrespective of changes in PV circumstances [26]-[27]. Investigators have implemented different MPPT frameworks and techniques over the past few decades. А вв converter is deployed in this research to attain the optimum power output of the PV system. Figure 6 illustrates the control schematic for the в-в converter.

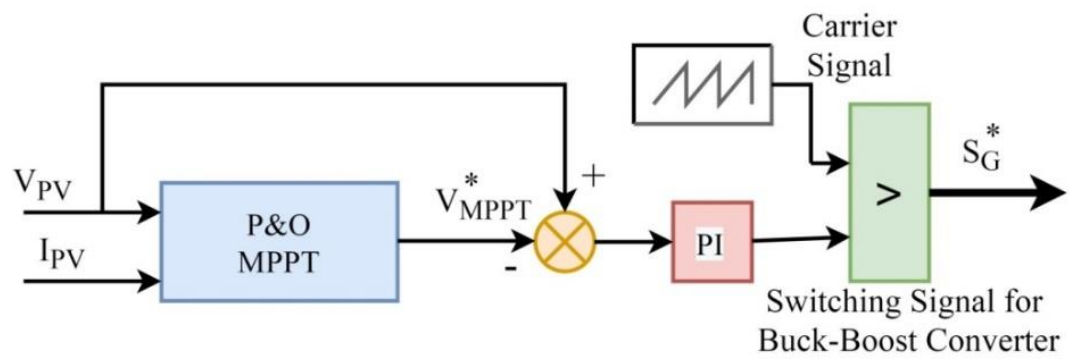

Figure 6. Controller diagram of buck-boost converter

The Perturb \& observe (P\&O) MPPT element is a fundamental part of this figure. In combination with the instantaneous current and voltage of the SPV system, this element can illustrate a pertinent voltage reference. Additionally, the reference voltage of this element will be progressively increased to track the optimum value by this element. The в-в converter controls to attain the voltage of the SPV system at its reference value. This technique has been employed because of its use of a simplistic but often robust approach.

\section{RESULTS AND DISCUSSION}

The efficiency of the presented Autonomous Hybrid Solar-Wind System (AHSWS) in various mechanical and electrical systems is indicated in figures 7-8. The simulation design of the implemented system is a built-in SIMPOWER software kit of MATLAB. The PV panel and wind turbine are simulated utilize the implanted MATLAB feature. Furthermore, the efficiency of the AHSWS at various wind speeds and regular solar irradiance as displayed in figure 7-8 respectively. Both situations examine the MPPT approach on differing wind speeds and PV radiation.

\subsection{Efficiency of ahsws in differing $P V$ radiation with continual load and wind velocity}

The system efficiency of AHSWS in differing PV radiation with continual load and wind velocityis displayed in Figure 7. The above scheme is operating at a wind velocity of $7.0 \mathrm{~m} / \mathrm{s}$ and solar global irradiation of $700.0 \mathrm{~W} / \mathrm{m}^{2}$ at time $\mathrm{t}=5.0 \mathrm{~s}$, the solar irradiation is raised to nearly $800.0 \mathrm{~W} / \mathrm{m}^{2}$ at the proportion of $400.0 \mathrm{~W} / \mathrm{m}^{2} / \mathrm{s}$ and afterward, it is decreased to $700.0 \mathrm{~W} / \mathrm{m}^{2}$ again starting from $\mathrm{t}=6.20 \mathrm{~s}$ at the similar level. The device is supposed to supply rated frequency and voltage from the PV, utilizing an MPPT controller. 

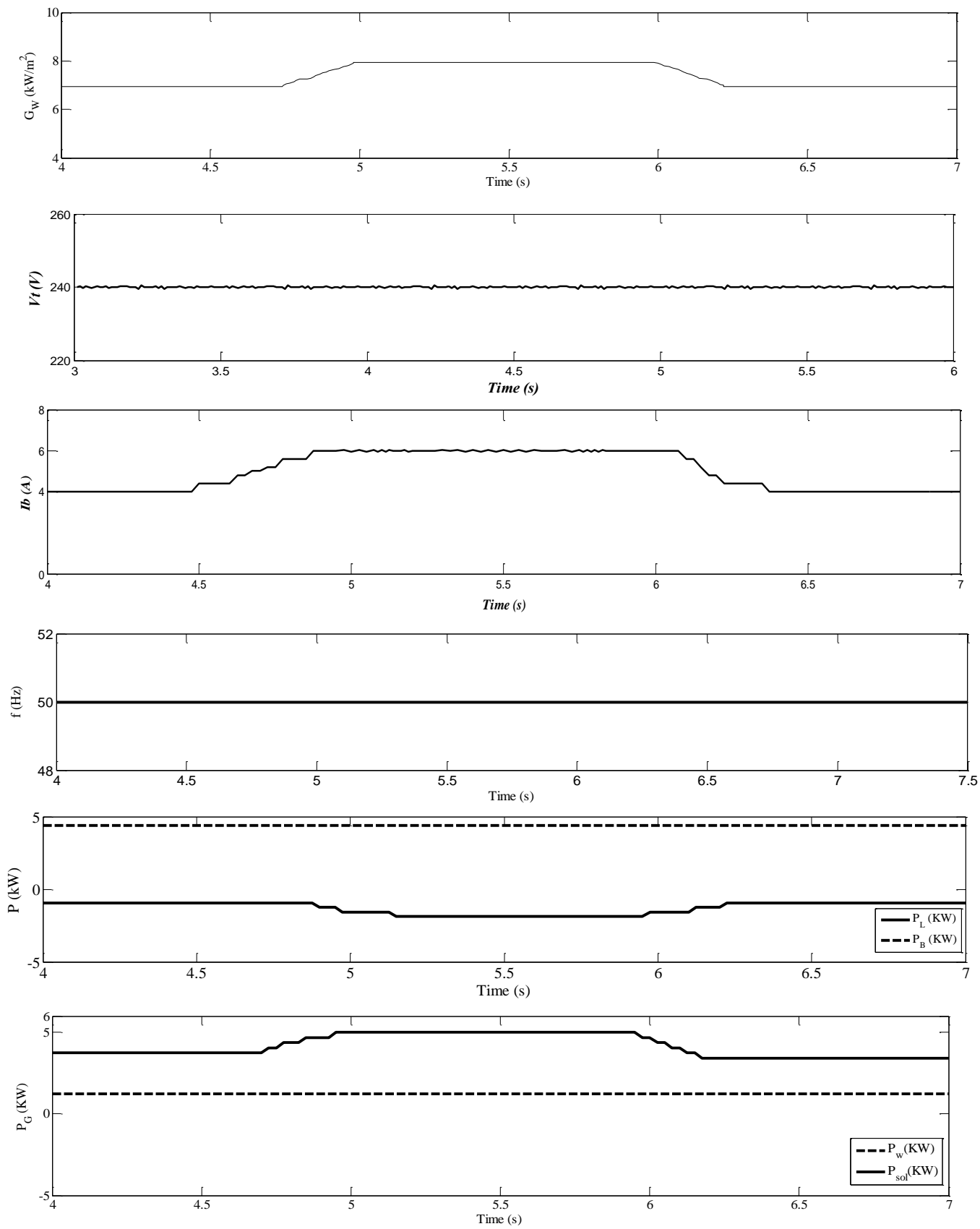

Figure 7. AHSWS efficiency at changing solar irradiations

\subsection{Efficiency of AHSWS in differing wind velocity with continual load and PV radiation}

The system efficiency of AHSWS in differing wind velocity with continual load and PV radiation is displayed in Figure 8. At the moment of beginning, solar panels are exposed to solar radiation of $800.0 \mathrm{~W} / \mathrm{m} 2$, and wind turbines to wind velocity of $7.0 \mathrm{~m} / \mathrm{s}$. The $3 \phi$ balanced loads of $1.0 \mathrm{kVAR}$ and $4.0 \mathrm{~kW}$ in the star link are connected at the common coupling Point. At the following wind velocity, the generator velocity of $153.34 \mathrm{rad} / \mathrm{s}$ is achieved. In compliance with at $4.85 \mathrm{~s}$, the wind velocity is increased to $7.50 \mathrm{~m} / \mathrm{s}$ as well as the speed of the generator is raised to $166.7 \mathrm{rad} / \mathrm{s}$. Wind velocity was decreased to $7.0 \mathrm{~m} / \mathrm{s}$ at $7.20 \mathrm{~s}$, with the same level of shift. Although, the discrepancy in the generator output and turbine in the electrical grid; voltage and frequency are not affected by the difference in wind velocity. After several cycles the transients die out device reaches its maximum speed proportional to $C_{p_{-} \text {max }}$ displaying an MPPT system operating in the wind control system. 

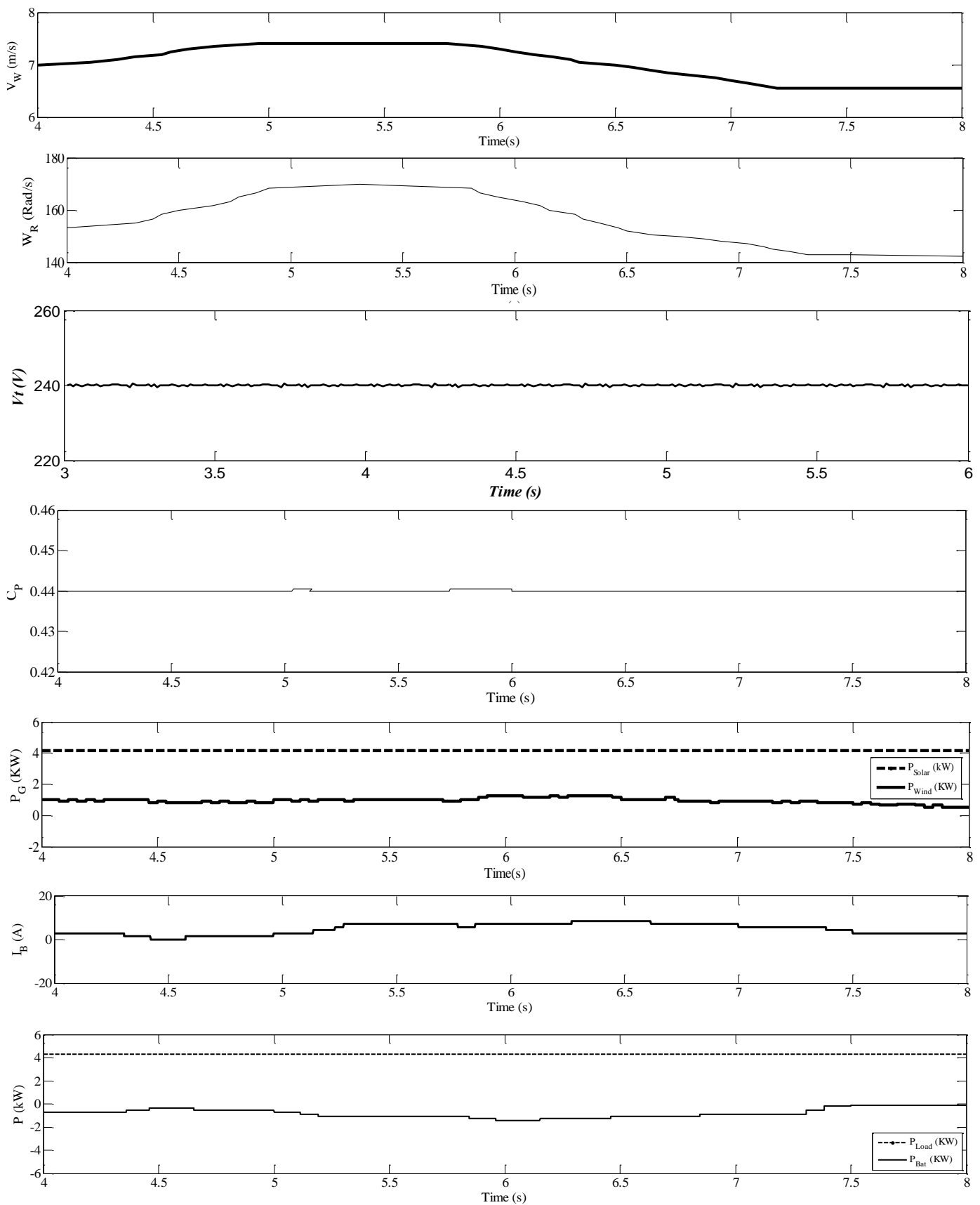

Figure 8. AHSWS efficiency at changing wind velocity

\section{CONCLUSION}

A 3申 4-wire AHSWS model has been developed, which demonstrates its efficiency. A detailed design process is provided to ensure accurate ratings and specifications for the components of the AHSWS. The proposed AHSWS wind turbine with DFIG and solar PV panel is been establish able to deliver quality power to the users. The device has an MPPT function to obtain optimum efficiency. The implemented AHSWS has been shown to achieve optimum efficiency under various mechanical, electrical, circumstances. The AHSWS has demonstrated the capability of tracking maximum power, neutral current mitigation, the removal of harmonics, and load balancing in addition to control of frequency and voltage; under various mechanical, electrical, dynamic conditions. 


\section{APPENDIX}

The modeling and simulation of Autonomous Hybrid Solar-Wind System (AHSWS) has been carried out by using the set parameters and its value, DFIG and PV Parameters. $\mathrm{P}_{\text {rated }}=4.0 \mathrm{~kW}, V_{\text {stator }}=400 \mathrm{~V}$, Rotor shaft speed=1500 RPM, Operating frequency=50 Hz, $I_{s}=11.5 \mathrm{~A}, R_{s}=1.35 \Omega, R_{r}=1.708 \Omega$, Pole pairs $=2, L_{m}=229$ $\mathrm{mH}$ and $L_{r}=83.16 \mathrm{mH}$. Model name PV $=$ MLE260HD, Maximum power rating $=235.0 \mathrm{Wp}$, PV cell Open circuit voltage $=0.6252 \mathrm{~V}$, PV module Open circuit voltage $\left(V_{o c v}\right)=38.20 \mathrm{~V}$, PV cell MPP voltage $=0.5061, \mathrm{PV}$ module Short circuit current=8.984A, PV cell MPP current=8.3A, $N_{s}=8, N_{p}=3$

\section{REFERENCES}

[1] O. P. Mahela, B. Khan, H. H. Alhelou and P. Siano, "Power Quality Assessment and Event Detection in Distribution Network with Wind Energy Penetration Using Stockwell Transform and Fuzzy Clustering," in IEEE Transactions on Industrial Informatics, vol. 16, no. 11, pp. 6922-6932, Nov. 2020, DOI: 10.1109/TII.2020.2971709.

[2] Parida A, Chatterjee D, "An Improved Control Scheme for Grid Connected Doubly Fed Induction Generator Considering Wind-Solar Hybrid System," International Journal of Electrical Power \& Energy Systems. vol. 77, pp. 112-122, 2016.

[3] Li K, Xu H, Ma Q, et al. "Hierarchy Control of Power Quality for Wind-Battery Energy Storage System," IET Power Electron, vol. 7, no. 8, pp. 2123-2132, 2014.

[4] Diaz-Gonzalez F, Sumper A, Gomis-Bellmunt O, et al. "Energy management of flywheel-based energy storage device for wind power smoothing," Applied Energy, vol. 110, pp. 207-219, 2013.

[5] Ma T, Yang H, Lu L, "Feasibility study and economic analysis of pumped hydro storage and battery storage for renewable energy power Island," Energy Convers Management, vol. 79, pp. 387-397, 2014.

[6] R. Cardenas, R. Pena, S. Alepuz and G. Asher, "Overview of Control Systems for the Operation of DFIGs in Wind Energy Applications," in IEEE Transactions on Industrial Electronics, vol. 60, no. 7, pp. 2776-2798, 2013.

[7] Om prakash Mahela, Baseem Khan, Hassan Haes Alhelou, Suddep Tanwer, "Assessment of Power Quality in the Utility Grid Integrated with Wind Energy Generation,” IET Power Electronics, vol. 13, no. 13, pp. 2917 - 2925, 2020 .

[8] G. Carrasco, C. A. Silva, R. Peña and R. Cárdenas, "Control of a Four-Leg Converter for the Operation of a DFIG Feeding Stand-Alone Unbalanced Loads," in IEEE Transactions on Industrial Electronics, vol. 62, no. 7, pp. 46304640, July 2015, DOI: 10.1109/TIE.2014.2364155.

[9] A. Parida, S. Choudhury and D. Chatterjee, "Microgrid Based Hybrid Energy Co-Operative for Grid-Isolated Remote Rural Village Power Supply for East Coast Zone of India,” in IEEE Transactions on Sustainable Energy, vol. 9, no. 3, pp. 1375-1383, July 2018, DOI: 10.1109/TSTE.2017.2782007.

[10] Parida A, Chatterjee D, "Cogeneration Topology for Wind Energy Conversion System Using Doubly-Fed Induction Generator," IET Power Electron, vol 9, no.7, pp. 1406-1415, 2016.

[11] 18. A. Parida, D. Chatterjee. "Stand-Alone AC-DC Micro Grid-Based Wind-Solar Hybrid Generation Scheme with Autonomous Energy Exchange Topologies Suitable for Remote Rural Area Power Supply," Int Trans Electr Energy Syst, vol. 28, no. 4, pp. 1-13, 2018.

[12] Parida A, Chatterjee D, "Integrated DFIG-SCIG-Based Wind Energy Conversion System Equipped with Improved Power Generation Capability," IET Generation Transmission Distribution, vol. 11, no. 15, pp. 3791-3800, 2017.

[13] Parida A, Chatterjee D, "Model-based loss minimisation scheme for wind-solar hybrid generation system using (grid-connected) doubly fed induction generator," IET Electrical Power Appl, vol. 10, no. 6, 548-559, 2016.

[14] G. D. Marques, S. M. A. Cruz and M. F. Iacchetti, "Minimum-Loss Control Strategy for a Dual-VSI DFIG DC System," in IEEE Transactions on Industrial Electronics, vol. 67, no. 10, pp. 8175-8185, Oct. 2020, DOI: 10.1109/TIE.2019.2952822.

[15] C. Wu, P. Cheng, H. Nian and F. Blaabjerg, "Rotor Current Oriented Control Method of DFIG-DC System Without Stator Side Sensors," in IEEE Transactions on Industrial Electronics, vol. 67, no. 11, pp. 9958-9962, Nov. 2020, DOI: 10.1109/TIE.2019.2956415.

[16] R. M. Prasad and M. A. Mulla, "Mathematical Modeling and Position-Sensorless Algorithm for Stator-Side FieldOriented Control of Rotor-Tied DFIG in Rotor Flux Reference Frame," in IEEE Transactions on Energy Conversion, vol. 35, no. 2, pp. 631-639, June 2020.

[17] Shukla R, Tripathi RK, Thakur p, "DC Grid/Bus Tied DFIG Based Wind Energy Systems," Renew Energy, vol. 108, pp. 179-193, 2017, https://DOI.org/10.1016/j.renene.2017.02.064.

[18] Sukla RD, Tripathi RK, "Instantaneous Direct Voltage Control and Frequency Control in Dc Grid Tied DFIG Based Wind Energy System,” Electrical Power Energy Syst, vol. 100, pp. 309-319, 2018.

[19] R. G. Wandhare and V. Agarwal, "Novel Integration of a PV-Wind Energy System with Enhanced Efficiency," in IEEE Transactions on Power Electronics, vol. 30, no. 7, pp. 3638-3649, July 2015, DOI: 10.1109/TPEL.2014.2345766.

[20] Fsaha Mebrahtu Gebru, Baseem Khan, Hassan Haes Alhelou, "Analyzing Low Voltage Ride Through Capability of Doubly Fed Induction Generator Based Wind Turbine," Computers \& Electrical Engineering, vol. 86, pp. 106727,2020 
[21] Arjun Kumar, G. B, Shivashankar, "Efficient Solar Integrated Doubly Fed Induction Generator for Wind Energy Harnessing," Recent Advances in Electrical \& Electronic Engineering (Formerly Recent Patents on Electrical \& Electronic Engineering), vo. 13, no. 12, pp. 723 - 735, 2020.

[22] G. B. Arjun Kumar, Shivashankar and Keshavamurthy, "Design and Control of Solar-Wind Integrated Conversion System with DFIG for Maximum Power Point Tracking," 2020 International Conference on Recent Trends on Electronics, Information, Communication \& Technology (RTEICT), Bangalore, India, 2020, pp. 292-298, DOI: 10.1109/RTEICT49044.2020.9315701.

[23] G. B. Arjun. Kumar, Shivashankar, N. Sujay, P. Tejas, P. Srikanth and Y. T R, "Design and Implementation of Wireless Sensor Network based Smart DC Grid for Smart Cities," 2019 4th International Conference on Recent Trends on Electronics, Information, Communication \& Technology (RTEICT), Bangalore, India, 2019, pp. 14531458, DOI: 10.1109/RTEICT46194.2019.9016798.

[24] G. B. Arjun Kumar, Shivashankar and B. Shree Ram, "Hybrid PV-Wind Driven Generator Supplying AC/DC Microgrid for Rural Electrification," 2018 3rd IEEE International Conference on Recent Trends in Electronics, Information \& Communication Technology (RTEICT), Bangalore, India, 2018, pp. 2283-2287, DOI: 10.1109/RTEICT42901.2018.9012328.

[25] R. Reddivari, Pruthviraj B G, M. Bharat and Arjun Kumar G B, "Modified gamma source inverter for fuel cell battery hybrid electric vehicles," 2016 Biennial International Conference on Power and Energy Systems: Towards Sustainable Energy (PESTSE), Bengaluru, India, 2016, pp. 1-6, DOI: 10.1109/PESTSE.2016.7516518.

[26] G. B. Arjun. Kumar, B. G. Pruthviraj, K. Y. K. Chethan and P. Rashmi, "Design and implementation of peltier based solar powered portable refrigeration unit," 2017 2nd IEEE International Conference on Recent Trends in Electronics, Information \& Communication Technology (RTEICT), Bangalore, India, 2017, pp. 1971-1974, DOI: 10.1109/RTEICT.2017.8256943.

[27] P. Attavane, G. B. Arjun, R. Radhakrishna and S. R. Jadav, "Solar powered portable food warmer and cooler based on peltier effect," 2017 2nd IEEE International Conference on Recent Trends in Electronics, Information \& Communication Technology (RTEICT), Bangalore, India, 2017, pp. 1975-1978, DOI: 10.1109/RTEICT.2017.8256944. 